\title{
CONGENITAL HYPOPLASIA OF DEPRESSOR ANGULARIS MUSCLE
}

Rajendran¹, Manil Muhammed ${ }^{2}$, Kailash Chandran ${ }^{3}$, Abdul Shikhoor ${ }^{4}$, Princy ${ }^{5}$

\section{HOW TO CITE THIS ARTICLE:}

Rajendran, Manil Muhammed, Kailash Chandran, Abdul Shikhoor, Princy. "Congenital Hypoplasia of Depressor Angularis Muscle". Journal of Evolution of Medical and Dental Sciences 2014; Vol. 3, Issue 44, September 15; Page: 10793-10795, DOI: 10.14260/jemds/2014/3406

INTRODUCTION: Asymmetric crying facies in a newborn is a rare condition caused by congenital hypoplasia of depressor angularis oris muscle [CHDAOM] on one side of the mouth. Other causes are facial nerve compression, often as birth trauma or abnormal facial nerve development. CHDAOM is reported to be associated with major congenital anomalies in $45-70 \%$ of cases. ${ }^{1,2}$ We report a case of isolated unilateral CHDAOM in a neonate.

KEYWORDS: Depressor angularis oris, Congenital anomaly, Asymmetric crying facies.

CASE REPORT: A male baby was born at term in our hospital by elective cesarean section to a 19 year old primigravida. She had received routine neonatal care and her pregnancy was uncomplicated. The birth weight was 2460 grams. There was no history of birth trauma no history of congenital anomalies in the family.

The baby had symmetric facies while sleeping. When he cried, the angle of mouth was seen deviated to the right and downwards, while the opposite corner or mouth did not move. The wrinkles on the forehead and nasolabial folds were symmetrical. The orbicularis occuli, frontalis, zygomaticus and mentis functioned normally. A skin tag and another warty skin lesion were present on the right cheek; the pinna was normal. His vital parameters were stable. He had no difficulty in feeding.

Further clinical examination revealed no other noticeable congenital anomalies and systemic examination including cardiovascular system was within normal limits. Tests for hearing and ophthalmology assessment were normal. Roentgenogram, ultrasonography and echocardiography did not reveal any congenital defect. The thyroid function tests, blood counts, serum electrolytes and calcium were normal. He was given routine newborn care and immunization. He was discharged on the fifth postnatal day and is kept under follow up.

DISCUSSION: Asymmetric crying facies (ACF), also called Cayler cardiofacial syndrome, partial unilateral facial paresis and hypoplasia of depressor anguli oris muscle, 3 is a minor congenital anomaly caused by agenesis or hypoplasia of the depressor anguli oris muscle, one of the muscles that control the movements of the lower lip. The incidence of CHDAOM is approximately 3-6/1000 live birth and is often confused with facial nerve palsy. ${ }^{1,2}$

This unilateral facial weakness is first noticed when the infant cries or smiles, affecting only one corner of the mouth and occurs on the left side in nearly $80 \%$ of cases. It is associated with other birth defects in more than $50 \%$ of cases. When the hypoplasia of the depressor anguli oris muscle is associated with congenital cardiac defects, the term 'Cayler cardiofacial syndrome' is used.

Asymmetry of facial movements in a newborn infant suggests $7^{\text {th }}$ nerve palsy caused by birth trauma inflicted by forceps blades or pressure against the maternal sacrum or the possibility of intracranial hemorrhage with or without skull fracture. Also to be considered in congenital mal development of the $7^{\text {th }}$ cranial nerve nucleus, the nerve itself, and the surrounding soft tissues. ${ }^{4}$ 
CHDAOM at one corner of the mouth is a relatively common minor anomaly that is easily recognizable clinically; however, it must be distinguished from facial palsies of traumatic or congenital origin. In CHDAOM one corner of the mouth does not move downward and outward symmetrically with the other; asymmetry is particularly evident when the child is crying. Forehead wrinkling, eye closure, nasolabial fold depth and tearing are symmetrical, and mentalis function is normal. Palpable thinning of the lateral portion of the lower lip is usually present on the affected side. Conduction times and nerve excitability studies are normal. ${ }^{4}$

CHDAOM is a benign condition that does not interfere with speech or feeding. The problem is essentially cosmetic. ${ }^{5}$ The best time for diagnosis is careful physical examination of newborn and if present, neonate should be screened for associated anomalies. The importance of recognizing CHDAOM lies in the fact that there is strong association of this anomaly with other significant anomalies. In an isolated anomaly, no treatment is required because the asymmetry is not noticeable in a grown up child. ${ }^{5}$

\section{REFERENCES:}

1. Lin DS, Huang FY, Lin SP, et al. Frequency of associated anomalies in congenital hypoplasia of depressor angularis oris muscle: a study of 50 patients. Am J Med Genet 1997; 71: 215-8.

2. Caksen H, Odabas D, Tuncer 0 , et al. A review of 35 cases of asymmetric crying facies. Genet Couns 2004; 15: 159-65.

3. Online 'Mendelian Inheritance in Man' (OMIM) 125520.

4. Nelson KB, Eng GD. Congenital hypoplasia of the depressor anguli oris muscle: Differentiation from congenital facial palsy. J. Pediatr. 1972; 81: 16-20.

5. Col. Gupta R, Brig. Prasad L. Congenital hypoplasia of depressor angularis oris muscle, MJAFI 2009; 65: 188-189.

Diagram 1: [CHDAOM] Angle of mouth deviated to the right and downwards.

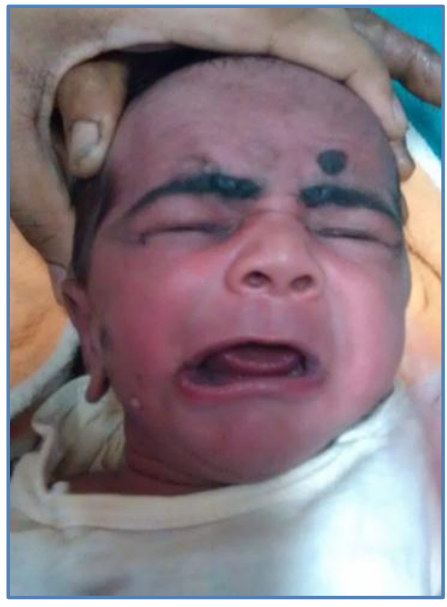

Diagram 1 


\section{AUTHORS:}

1. Rajendran

2. Manil Muhammed

3. Kailash Chandran

4. Abdul Shikhoor

5. Princy

\section{PARTICULARS OF CONTRIBUTORS:}

1. Professor and HOD, Department of Paediatrics, Azeezia Medical College and Hospital, Meeyannoor.

2. Assistant Professor, Department of Paediatrics, Azeezia Medical College and Hospital, Meeyannoor.

3. Professor, Department of Paediatrics, Azeezia Medical College and Hospital, Meeyannoor.

4. Professor, Department of Paediatrics, Azeezia Medical College and Hospital, Meeyannoor.
5. Assistant Professor, Department of Paediatrics, Azeezia Medical College and Hospital, Meeyannoor.

\section{NAME ADDRESS EMAIL ID OF THE} CORRESPONDING AUTHOR:

Dr. Manil Muhammed, Assistant Professor, Department of Paediatrics, Azeezia Medical College and Hospital, Meeyannoor.

Email: anurajp04@gmail.com

Date of Submission: 03/09/2014. Date of Peer Review: 04/09/2014. Date of Acceptance: 09/09/2014. Date of Publishing: 12/09/2014. 